\title{
The impact of roster changes on absenteeism and incident frequency in an Australian coal mine
}

\author{
A Baker, K Heiler, S A Ferguson
}

Occup Environ Med 2003;60:43-49

See end of article for authors' affiliations

Correspondence to: Dr A Baker, Centre for Sleep Research, 5th Floor, CDRC Building, The Queen Elizabeth Hospital,

Woodville Road,

Woodville, South Australia, 5011 ;

angela.baker@unisa.edu.au

Accepted 5 June 2002
Background: The occupational health and safety implications associated with compressed and extended work periods have not been fully explored in the mining sector.

Aims: To examine the impact on employee health and safety of changes to the roster system in an Australian coal mine.

Methods: Absenteeism and incident frequency rate data were collected over a 33 month period that covered three different roster schedules. Period 1 covered the original 8-hour/7-day roster. Period 2 covered a 12-month period under a 12-hour/7-day schedule, and period 3 covered a 12-month period during which a roster that scheduled shifts only on weekdays, with uncapped overtime on weekends and days off (12-hour/5-day) was in place. Data were collected and analysed from the maintenance, mining, and coal preparation plant (CPP) sectors.

Results: The only significant change in absenteeism rates was an increase in the maintenance sector in the third data collection period. Absenteeism rates in the mining and CPP sectors were not different between data collection periods. The increase in the maintenance sector may be owing to: (1) a greater requirement for maintenance employees to perform overtime as a result of the roster change compared to other employee groups; or (2) greater monotony associated with extended work periods for maintenance employees compared to others. After the first roster change, accident incident frequency decreased in the CPP sector but not in the other sectors. There was no effect on incident frequency after the second roster change in any sector.

Conclusions: The current study did not find significant negative effects of a 12-hour pattern, when compared to an 8-hour system. However, when unregulated and excessive overtime was introduced as part of the 12-hour/5-day roster, absenteeism rates were increased in the maintenance sector. The combination of excessive work hours and lack of consultation with employees regarding the second change may have contributed to the overall negative effects.
T he proportion of the population working irregular or extended hours is increasing as a wider range of organisations and industries expand their operations. Shiftwork is traditionally defined as work conducted outside the "standard" 9 am-5 pm, five day week, and incorporates regular rotating shifts, irregular/on-call work, or a combination of both. Increased flexibility in the way that working hours are scheduled has led to a growth in non-standard and irregular work schedules, including compressed and intensive shift systems. In the Australian mining industry approximately $46 \%$ of employees work shiftwork, ${ }^{1}$ and recently, the Australian mining industry has seen an increase in compressed rosters, involving various configurations of 12-hour shifts. A recent national study of rostering arrangements in the Australian mining industry revealed that $53.6 \%$ of all sites surveyed had some form of 12-hour shift roster as their predominant arrangement. ${ }^{2}$

A change from 8-hour to 12-hour shifts (compressed work weeks) has both advantages and disadvantages for an organisation and employees. For a company, 12-hour shifts allow operation with reduced staffing levels, improve communication and reduce down-time owing to fewer shift changeovers, and increase productivity. ${ }^{3-6}$ For the worker, the benefits of a 12-hour roster include compression of the working week, reduced travelling time, longer blocks of non-work time (for example, social and family time) and the potential for increased remuneration. ${ }^{358}$ However, there are also significant challenges for both employers and employees, including management of fatigue, maintenance of safety standards and productivity targets, and preservation of employee health and wellbeing.
Individuals who work shiftwork are widely reported to suffer more health problems than dayworkers. For example, shiftworkers experience disrupted sleep patterns and increased incidence of sleep disorders, ${ }^{9}{ }^{10}$ in addition to a higher incidence of gastrointestinal problems and increased risk of cardiovascular disease. ${ }^{11}{ }^{12}$ Employee health problems contribute directly to absenteeism and reduced productivity. Because of the requirement for adequate recovery between work shifts, high fatigue levels can contribute to absenteeism. An individual's wellbeing and quality of life can be significantly affected by irregular and extended work hours. The temporal separation of employees from their families affects the individual, their partners, and children, ${ }^{79}$ and may also precipitate withdrawal manifested in absenteeism. ${ }^{13}$ Likewise, the isolation of the worker from the community reduces social interaction and interpersonal relationships. Therefore, the detrimental effects of shiftwork on health and wellbeing directly impact on employee quality of life, as well as the productivity of the organisation.

A further challenge facing shiftworkers is compromised workplace safety. Shiftwork, and in particular working time arrangements that include 12-hour shifts, predisposes employees to high levels of fatigue. Fatigue manifests itself in impaired physiological and cognitive performance, arising as a consequence of a range of factors including inadequate restorative sleep, the timing of work and break periods, and

Abbreviations: $\mathrm{Al}$, all incident; $\mathrm{AlFR}$, all incident frequency rate; ANOVA, analysis of variance; CPP, coal preparation plant 
Table 1 Number of employees in each sector

\begin{tabular}{llll}
\hline & Mining & Maintenance & CPP \\
\hline No. employees & $120-215$ & $110-205$ & $40-60$ \\
\hline
\end{tabular}

the length of work and break periods. ${ }^{14}$ In the case of 12-hour shift systems, fatigue arises as a result of long work hours as well as a reduced amount of time available for recovery between shifts. Fatigue was identified as a significant contributing factor in a number of large scale disasters, including the Exxon Valdez oil tanker grounding in Prince William sound, ${ }^{15}$ and the Chernobyl reactor accident. ${ }^{16}$ Increasingly, fatigue is being recognised as a significant risk factor for health and safety in workplaces employing shiftworkers. In response, roster schedules are being designed to minimise the potential for fatigue while maintaining productivity targets.

In the design of any roster schedule, a number of parameters can be manipulated to achieve the balance between health/safety, staffing requirements, and productivity. For example, the time at which a shift starts, the length of individual shifts, and the direction of shift rotation, are all aspects of a roster that can impact on both productivity and employees' capacity for recovery. With regard to health and safety, work schedules can affect absenteeism rates, error rates, and accident/incident rates. However, the difficulty with assessing the impact of rosters is that results can be sensitive to the workplace setting, specific work tasks, and the demographics of the population under investigation, in addition to the context in which the roster has been introduced. Previously, the majority of analyses have compared different shift systems across different workplaces. Despite this, real world epidemiological data, collected with minimal interference from investigators, provides invaluable information regarding the impact of roster schedules on employees. The current paper examines the effects on health and safety parameters of a change in roster design from 8-hour to 12-hour shifts, in the same workforce, undertaking the same tasks. Two variables were assessed: absenteeism rate and the timing and rate of workplace incidents.

\section{METHODS \\ Setting}

The setting was an open cut coal mine in Queensland, Australia in a daily commuting environment of approximately 30 minutes commuting time by car one way.

\section{Study population}

The study focused on three work areas in the mine: the mining sector, the maintenance sector, and the coal preparation plant (CPP). The work tasks were different in each sector. Mining employees were required to operate a range of heavy mobile equipment including trucks, loaders, bulldozers, excavators, and graders. Employees in the coal preparation plant were involved in driving bulldozers and loaders, computer monitoring in the control room, and work in the washery. Maintenance personnel worked primarily in the workshop or the field and were involved in electrical or mechanical maintenance tasks. Over the study period the number of employees in each sector varied (see table 1 ).

\section{Roster details}

The mine traditionally ran a backward rotating 8-hour/7-day roster, with day shift followed by night, then afternoon shift (fig 1A). A compressed 12-hour/7-day roster was implemented after extensive consultation with employees, on the understanding that the change was necessary to ensure the continued survival of the mine (fig $1 \mathrm{~B}$ ). The design conformed to a principle for 12-hour shifts that there should be no more than two consecutive night shifts, that shifts were not to be extended by overtime, and rostered days off were not to be used for overtime. The 7-day label refers to the fact that work shifts were scheduled on all seven days of the week, rather than to the length of the cycle. The roster change was accompanied by a reduction in employee numbers (of about 120 employees and contractors throughout the mine) and a pay increase for those remaining.

Twelve months later approximately half of the workforce was moved onto a 12-hour/5-day roster (fig 1C). The key differences with the 12-hour/5-day roster were that the weekends were nominally free (hence the label 5-day, as work shifts were only scheduled Monday to Friday) and there were three consecutive night shifts. Further, the previously agreed cap on overtime was removed for those on the 12-hour/5-day roster. The second round of changes was implemented without consultation with the workforce. The new roster was accompanied by a further reduction in staff numbers and a pay cut for those who were required to change roster (although overtime was available).

Timing of shifts was as follows: 8-hour roster: day shift 0700-1500, afternoon shift 1500-2300, night shift 2300-0700; 12-hour rosters: day shift 0600-1800, night shift 1800-0600.

\section{Data collection periods}

Three data collection periods spanned a total of 33 consecutive months. Period 1 (November 1997 to July 1998) covered the nine month period prior to the roster changes, during which the entire mine was on the backward rotating 8-hour/7-day schedule. Period 2 (August 1998 to July 1999) covered the 12 month period after the 12-hour/7-day roster was implemented across the entire site. Period 3 (August 1999 to July 2000) covered the 12 month period after the 12-hour/5-day schedule was implemented.

As mentioned, not all employees were involved in the change to the 12-hour/5-day schedule. All of the CPP employees (approximately 40), around two thirds of mining (approximately 110), and approximately half of the maintenance employees (approximately 65 ) went onto the 12-hour/ 5-day roster in August 1999.

\section{Measures}

\section{Absenteeism rate}

The number of employees who were recorded as absent from work during any shift (for any length of time) in a calendar month was determined retrospectively and calculated as a percentage of all employees in the reference group. The average monthly absenteeism rate for each recording period was calculated for the whole mine as well as for the mining, maintenance, and CPP sectors individually.

\section{All incident frequency rate}

Incidents were recorded using the all incident (AI) measure which incorporates all injuries or incidents, of all severities, including near misses. The all incident frequency rate (AIFR), calculated monthly, is the number of "all incidents" that occurred per million hours worked. The average monthly AIFR was calculated for the three recording periods in the mining, maintenance, and CPP sectors.

\section{Time of day of incident occurrence}

The AI data were separated according to the shift length (8-hour or 12-hour). The 8-hour roster covered the period from November 1997 to July 1998 and the 12-hour rosters covered the period from August 1998 to July 2000. The time of each incident was determined from occupational health and safety logs kept at the mine. The number of incidents that occurred in each hour across the 24 hour day was summed for both the 8-hour and 12-hour AI data. 
A

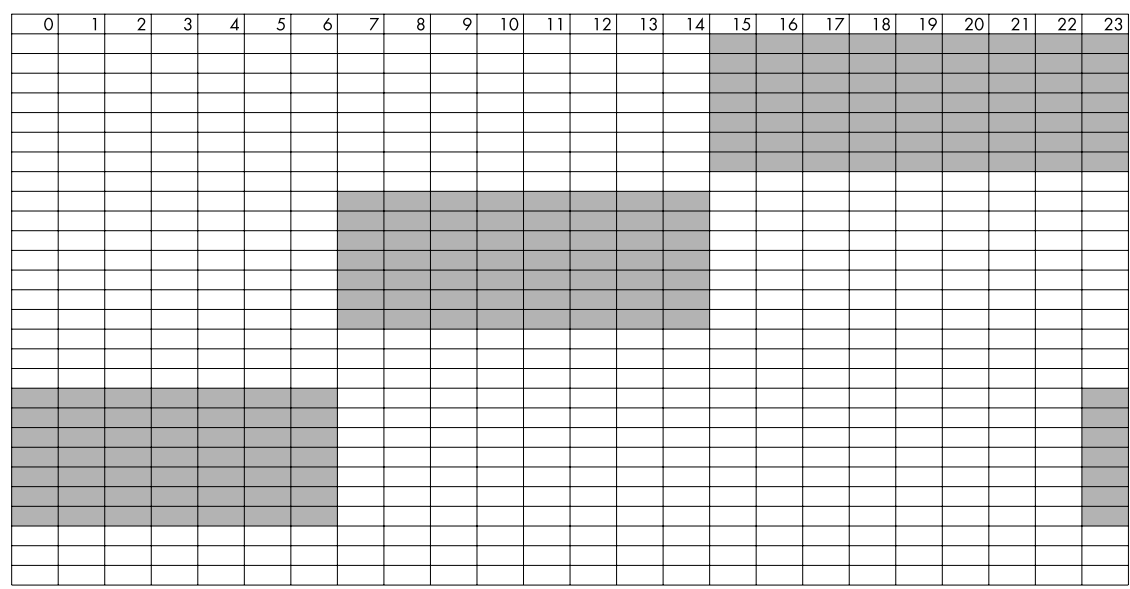

B

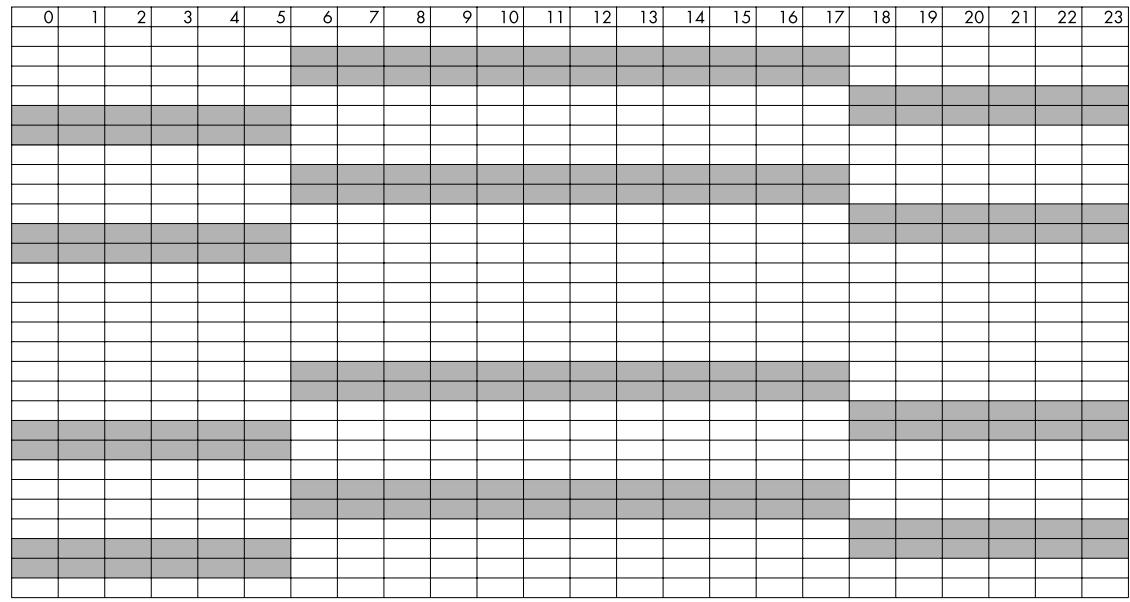

C

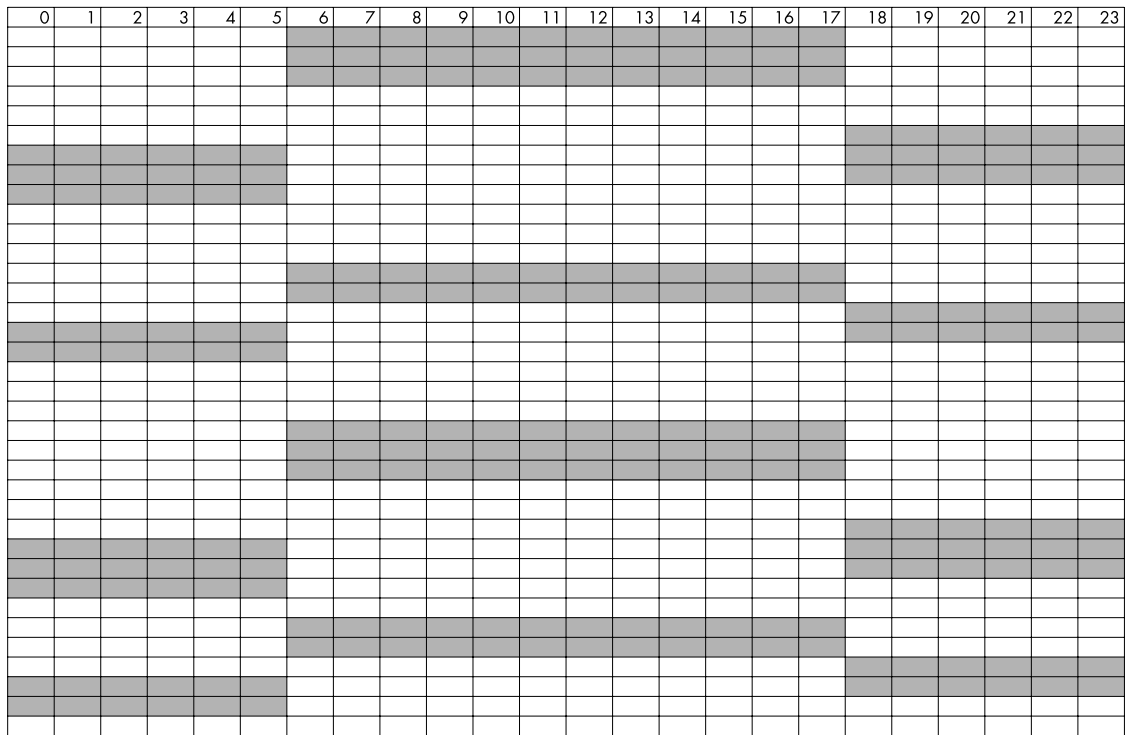

Figure 1 Graphic illustration of the three roster schedules used at the mine over the 33 month study period: (A) 8-hour/7-day roster; (B) 12-hour/7-day roster; (C) 12-hour/5-day shift.

\section{Data analysis}

To examine possible changes in the variables between data collection periods across the whole mine (absenteeism), as well as in the individual work areas of interest (absenteeism and AIFR), the data sets were analysed using factorial analyses of variance (ANOVA). Post hoc analyses were conducted using Fisher's protected least significant difference where required.

\section{RESULTS}

\section{Absenteeism}

The percentage of employees absent in each month for the 33 month period across the whole mine ranged from $1.6 \%$ to $4.4 \%$ per month. Factorial ANOVA indicated no change across collection periods in the average monthly absenteeism rate across the whole mine $(\mathrm{F}(2,31)=1.962$, $\mathrm{p}>0.05$ ) (fig 2). 


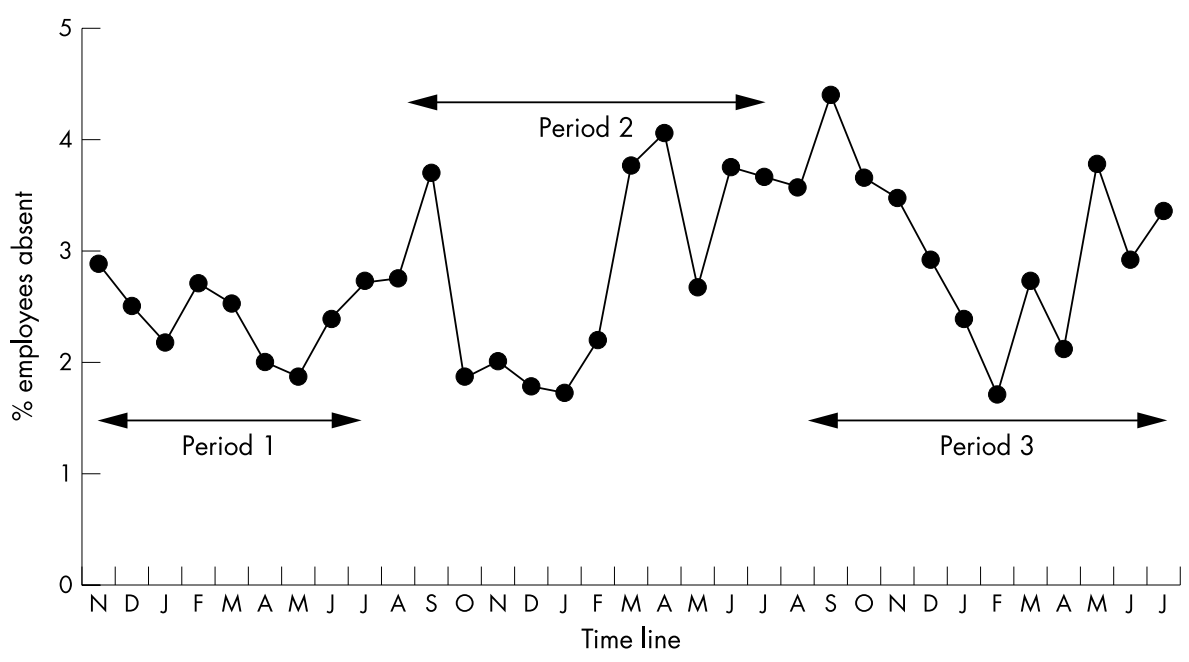

Figure 2 The average percentage of employees absent at any point in a calendar month, in the entire mine. Data were collected for 33 consecutive months from November 1997 to July 2000. Period 1 covers the 8-hour/7-day roster, period 2 covers the 12-month period after the change to the 12-hour/7-day roster, and period 3 covers the 12-month period after some employees changed to the 12-hour/5-day roster.

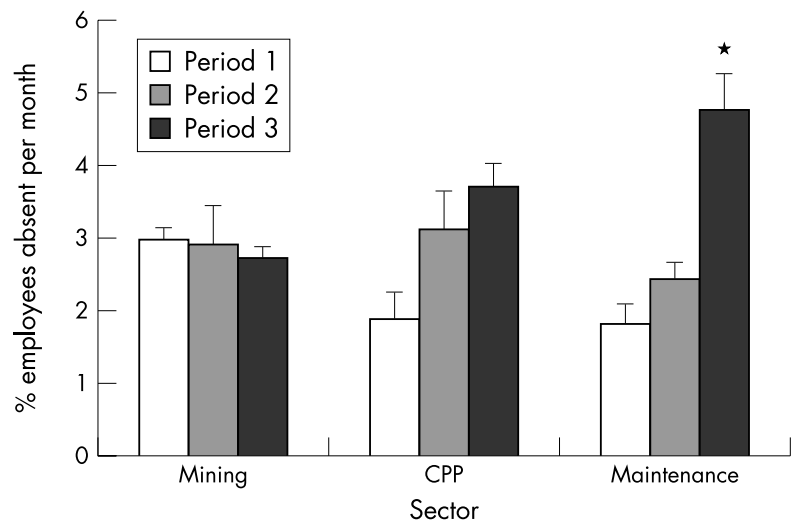

Figure 3 The average monthly absenteeism rate for each of the recording periods separated according to work sector. Data are mean (SEM) for 9 months (period 1), 12 months (period 2), and 12 months (period 3). The asterisk indicates a significant difference between period 3 and both periods 1 and 2 in the maintenance sector $(p<0.05)$.

Figure 3 shows the average monthly absenteeism rates in the three specific work areas examined, according to collection period. Results show no significant change between data collection period in the absenteeism rate in the mining sector $(\mathrm{F}(2,24)=0.166, \mathrm{p}>0.05)$. There was a trend for increased rates during the second $(3.11 \%)$ and third $(3.72 \%)$ collection periods within the CPP sector, compared to the first ( $1.87 \%)$, but this was not significant $(\mathrm{F}(2,24)=2.441, \mathrm{p}>0.05)$. In contrast, factorial ANOVA indicated that the average absenteeism rate in the maintenance sector was different between collection periods $(\mathrm{F}(2.24)=19.186, \mathrm{p}<0.05)$. Post hoc analysis determined that absenteeism rate was significantly higher during the third period compared to both the first and second periods in the maintenance sector (both $\mathrm{p}<0.05$ ) (fig 3 ).

\section{All incident frequency rate}

There was no significant difference found between collection periods in the AIFR in the mining $(\mathrm{F}(2,30)=1.321, \mathrm{p}>0.05)$ or maintenance $(\mathrm{F}(2,30)=0.342, \mathrm{p}>0.05)$ areas of the mine, as indicated by factorial ANOVA. However, there was a significant difference in AIFR in the CPP sector $(F(2,30)=3.41$, $\mathrm{p}<0.05)$. Post hoc analysis showed that the AIFR during the second period was significantly lower than during the first period in the coal preparation plant $(\mathrm{p}<0.05)$. The AIFR rose

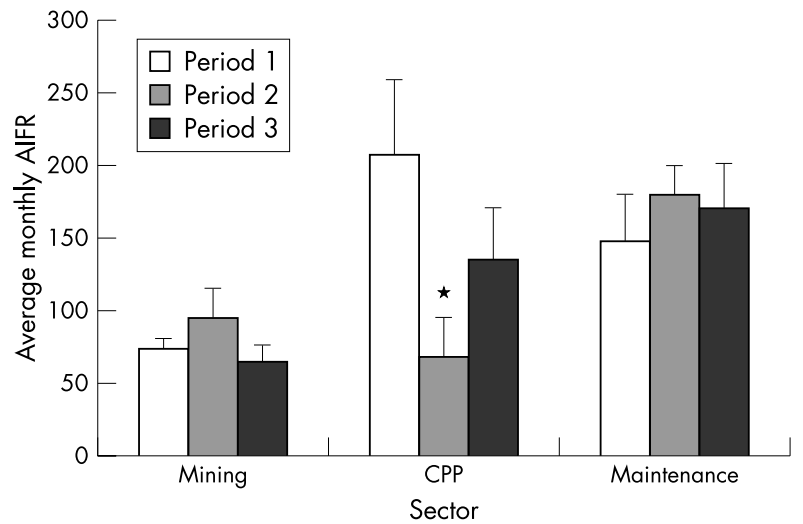

Figure 4 The average monthly AIFR for each of the recording periods separated according to work sector. Data are mean (SEM) for 9 months (period 1), 12 months (period 2), and 12 months (period 3). The asterisk indicates a significant difference between period 2 and both periods 1 and 3 in the coal preparation plant $(\mathrm{p}<0.05)$.

again in period 3, but was not significantly higher than the AIFR in period 2 (fig 4).

\section{Time of day}

Visual inspection of the AIFR data plotted according to the time of day of each incident allowed identification of "peak" incident times. On the 8-hour roster the highest number of incidents occurred between 0900 and 1000 on the day shiftthat is, approximately $2-3$ hours into the shift. On the afternoon shift, incidents were clustered between 1900 and 2000 during the afternoon shift (4-5 hours into the shift), and on the night shift between 0300 and 0500 (approximately 5 hours into the shift) (fig 5). On the 12-hour schedule the peaks occurred at 1100-1200 (5-6 hours into the shift) and 1500-1600 (9-10 hours into the shift) in the day shift, and 2200-2300 (4-5 hours into the shift) on the night shift (fig 5).

\section{DISCUSSION}

The changes in absenteeism and the AIFR between the three data collection periods were not consistent across the mine. An increase in absenteeism rate coincided with the implementation of the 12-hour/5-day schedule (period 3) in the maintenance sector but absenteeism did not change significantly in the mining sector and CPP. Further, the change from 8-hour to 

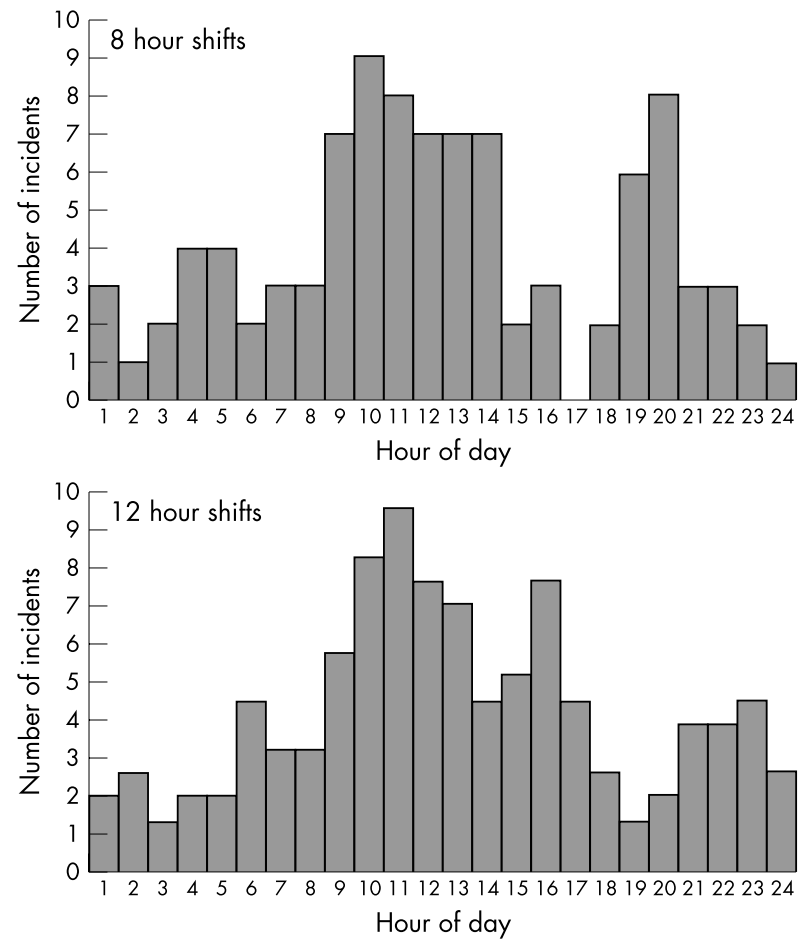

Figure 5 The number of incidents occurring in each hour across the day, separated according to the roster being worked at the time of the incident. The top panel represents incident data from the 8 -hour roster, and the bottom panel represents data pooled from both 12-hour rosters.

12-hour shifts coincided with a decrease in the AIFR only in the CPP. The results suggest that changes in absenteeism and incident frequency may have been dependent on the specific work environment. Further, inspection of the time of day of incident data pointed to a number of time points across the 24 hour period with an increased frequency of incidents.

The measures used to assess health and safety in the current study were absenteeism rate and the AIFR. There are few ethical or legal implications for an organisation in the supply of absenteeism and AIFR data. Both measures are readily available, easy to collate, and generally accurately documented, making them a practical and objective marker of employee health and safety. However, as with any data collected in "real world" settings, there are some limitations associated with the measures. Data pertaining to absenteeism and incident frequency rates of individuals was not available. Thus, any conclusions that are drawn from the current analysis can only be generalised from the populations under investigation. However, the current study is unique in that it is one of few published analyses of roster schedule changes within the same workplace.

Absenteeism may fluctuate in a workplace for a number of reasons. Health related absenteeism may fluctuate with the seasons (that is, colds and flu during winter); however, the three data collection periods covered similar times of the year, making it unlikely that seasonal factors played a significant role in any changes in absenteeism. Administrative control mechanisms associated with sick leave payment may also affect absenteeism levels. For example, some sites require medical certificates for absences of a single day, while others allow up to three without a report. However, in the current study no changes occurred to the administration mechanisms during the study period. There was a major change in October 1997; however, our data collection began in November 1997. Thus, we believe that the changes in absenteeism recorded at the mine site provide a useful marker of the effect of the rosters on employee health and wellbeing.
The implementation of the 12-hour/7-day roster schedule in the mine coincided with a period of lower absenteeism (after an initial high month), which was sustained for five months. Similarly, the introduction of the 12-hour/5-day rosters was also associated with a trend across the whole mine for a reduction in absenteeism rate. However, towards the end of the study period absenteeism had risen again. On face value, this suggests that employee health may have improved with the introduction of each roster. The longer blocks of time away may have allowed more opportunity for recovery from work, resulting in lower fatigue levels and increased wellbeing. Williamson ${ }^{17}$ examined the change from an 8-hour to a 12-hour roster in computer operators and also reported improvements in health and reduced feelings of tiredness. While this concurs with the current results, findings can be interpreted in a number of ways.

In addition to a marker of employee health, absenteeism can also be a manifestation of discontent and withdrawal from work..$^{13}$ Employees believed that the initial change to a 12-hour/7-day system was essential for the survival of the mine and may therefore have been positive about making the adjustment. The low levels of absenteeism may reflect a positive attitude of the workforce. Any aversion to the 12-hour roster may have manifested itself only after some months of exposure to the schedule. In turn, the 12-hour/5-day system scheduled shifts only on weekdays, possibly resulting in increased worker satisfaction. After a period of time, the requirements of overtime may have negated the positive aspects of the 12-hour/5-day roster (that is, free weekends), resulting in reduced worker satisfaction. In addition to a marker of worker satisfaction, changes in absenteeism rate may also be associated with changes in the make-up of the workforce.

As previously mentioned, the implementation of the 12-hour/7-day roster was accompanied by significant staff reduction (approximately 120 employees). Without specific details about individual employees, it is not possible to determine whether that particular group of employees were poor performers in terms of absenteeism and/or safety.

The implementation of the 12-hour/5-day schedule coincided with a significant increase in the absenteeism rate in the maintenance sector only. There was a trend for higher absenteeism in the CPP sector, coincident with both schedule changes, but the change was not significant. The demands of the 12-hour/5-day roster schedule, which included overtime assigned at the end of regular shifts or on scheduled days off, may have placed increased stress on the health and wellbeing of the maintenance sector employees. Reduced opportunity for sleep can result in significant sleep deprivation, which in turn can result in irritability, depression, and a general reduction in quality of life. ${ }^{18}$ Further, as sleep is believed to serve a restorative function for both mind and body, ${ }^{19}$ sleep loss can lead directly to significant health problems. Unfortunately, data were not available regarding individual absenteeism. Therefore, we are unable to determine whether a distinct population has contributed to any increased health related absenteeism.

As mentioned above, absence can also be a mechanism of withdrawal from work, rather than being associated solely with increased morbidity. ${ }^{13}$ In the maintenance sector only half of the employees went on to the 12-hour/5-day roster. It is possible therefore, that discontent with the new schedule may have been exaggerated by the fact that colleagues in the same sector did not have to work the excessive overtime required to secure a similar wage. Further, maintenance staff worked either in the workshop or in the field, and while rotation between the sites was recommended, in practice, it occurred sporadically. As a result, workers were often confined to the workshop for extended periods, an unstimulating and isolated environment. The monotony of the work tasks, exacerbated by the extended shifts, may have resulted in reduced worker satisfaction. Irregularly scheduled overtime, sometimes at the 
end of a regular 12-hour shift, extended the hours at work and would have interfered with workers' ability to predict and regulate daily activities, such as family commitments and sleep. Smith and colleagues ${ }^{5}$ conclude from a review of the 8 versus 12-hour shift literature that "the issue of overtime is an area of some concern with 12-hour shift systems". While the conclusion pertains predominantly to fatigue and safety, dissatisfaction with work hours may also result in higher absenteeism. Previous studies have reported improvements in physical health and sleeping patterns associated with a change from an 8 - to a 12 -hour schedule. ${ }^{48}$ Thus, the current results highlight the importance of careful design of compressed rosters and the need to ensure that overtime is controlled. We found no significant, sustained increase in the absenteeism rate in the mining or CPP sectors, suggesting that the changes were specific to the maintenance sector and potentially associated with the high levels of overtime only worked by maintenance employees.

The other measure employed in the current study, the AIFR, provides a broad snapshot of safety on site. The measure includes first aid treatments, medically treated injuries, lost time incidents, equipment damage involving human error with consequence for injury, and near misses. The consistency of reporting safety incidents incorporated in the AIFR can be variable between organisations. Near misses are sometimes under reported, "lost time" can be manipulated by returning injured workers to lighter duties, and there can be significant variability in the accuracy of equipment damage reports. However, as the reporting of incidents within the current organisation was consistent, the data are comparable across time in each sector. Finally, although the AIFR does not differentiate between incidents in terms of severity, the measure remains the most readily available and reliable marker of the overall safety environment of an organisation.

Increased error rates have been cited as a disadvantage of 12-hour shifts. ${ }^{50-22}$ The safety record of the rosters was examined using the AIFR. The AIFR in the maintenance and mining sectors did not change between data collection periods, suggesting that the frequency of incidents was unaffected by roster changes in these areas. These results concur with a previous study of roster changes in an underground mine, which showed that fatigue sensitive behavioural and physiological measures were not different after the change to 12-hour shifts. ${ }^{23}$ Interestingly, with the initial change to the 12-hour/7day roster the AIFR in the CPP dropped dramatically. Thereafter, a non-significant rise in the AIFR occurred with the subsequent change to the 5 -day roster. The data may indicate that the 12-hour/7-day roster was conducive to higher safety levels specifically for the tasks required in the CPP. However, it is unknown whether the decrease in incidents was due directly to the 12-hour shift schedule, or whether there was an unusually high number of incidents in the first data collection period, related to factors such as higher production levels, different employee make-up, or higher levels of overtime. Data were not available prior to the first collection period. The nonsignificant increase in AIFR after the introduction of the 12-hour/5-day roster and the increased overtime worked in the CPP area may also point to potential problems with the roster.

An analysis was done on the 24 hour aspects of the AIFR trends at the mine. Limited data were available on personnel numbers in the mine during the collection periods. More employees were rostered on during the day shifts of both rosters (predominantly contractors and maintenance personnel) and overtime was often scheduled during the day shifts. Thus, it is not surprising that the majority of incidents occurred during the day shift. Outside daylight hours the peak incident times varied according to the design of the shift. In the 8-hour roster there was a peak between 1900 and 2000 in the afternoon shift and between 0300 and 0500 on the night shift. The 0300-0500 time point coincides with the well docu-

\section{Main messages}

- The process by which changes to shift schedules are imple mented within a workplace is important to the resultant effects on employee health and safety.

- The regulation of overtime, particularly in the mining sector, is important, as the time for recovery, especially between extended (12-hour) shifts will be greatly reduced.

- The impact of extended work hours on employee health and safety may be highly dependent on the specific work tasks involved.

- The measures of absenteeism and incident frequency as gathered from available data on-site, although not ideal, provide adequate markers for employee health and safety.

- The effects of time of day on performance should be taken into consideration when scheduling tasks within a shift, and when scheduling the start and end times of shifts.

\section{Policy implications}

- The current study has implications for the regulation of amount of overtime worked, especially in the mining sector.

- The scheduling of tasks within shifts should be planned such that high risk tasks are performed during periods of highest alertness.

- The number and timing of breaks during shifts, in addition to the use of naps, should be considered as part of scheduling policy.

mented nadir in the circadian rhythms of alertness and performance ${ }^{24-26}$ Therefore, incidents during this time period may be attributable to impaired performance and decreased alertness. Strategic timing of breaks or shift changeover, to minimise the degree of alertness and performance impairment, may reduce the incident frequency. However, circadian factors are not the sole contributor to decreased safety. Hour on shift (or time on task) is also a significant factor in the rate of incidents and accidents in the workplace.

In general, the literature suggests that more than nine hours on task can expose the worker to extremely high risk for accidents and incidents. ${ }^{25}{ }^{27}$ In line with this, the current study found peaks in incident rates on the 12-hour rosters in the tenth hour of the day shift and the twelfth hour of the night shift. Interestingly, Hanecke and colleagues ${ }^{27}$ reported an increase in accident risk across the German working population up to the first five hours at work. Similarly, an investigation of time on task effects in the transport industry showed increased risk up to four hours on task. ${ }^{28}$ In the current study, the 1000-1100 and 1900-2000 peaks in the 8-hour roster and the 2200-2300 peak in the 12-hour roster occurred four to five hours into the shift. Scheduling of high risk tasks should be minimised around these time points, and/or breaks strategically planned.

Although previous research on the impact of shift schedule changes in the same subject population is limited, in general the data indicate that well designed 12-hour shifts that conform to best practice scheduling principles and practices are a viable option to 8-hour shifts. The key proviso is that 12-hour shifts should not be extended by overtime and employees should not be brought in on their rostered days off to work additional shifts. While we acknowledge that the current data set has some limitations in terms of individual details, we believe that the results provide invaluable information about the effects of roster changes within an organisation. The findings reiterate that the specific work task involved may mediate the effects of roster changes on employee groups. Further, specific time points across the 24-hour period are associated with an increased probability of incidents. Strategic timing of breaks in addition to the 
judicious scheduling of work tasks within a shift, are mechanisms by which time of day related incidents may be minimised.

\section{Authors' affiliations}

A Baker, S A Ferguson, The Centre for Sleep Research, University of South Australia, 5th Floor, CDRC Building, The Queen Elizabeth Hospital, Woodville Road, Woodville, South Australia, Australia 5001

K Heiler, ACCIRT, Institute Building H10, University of Sydney, Sydney, Australia

\section{REFERENCES}

1 Australian Bureau of Statistics. Working arrangements. Australia: Australian Bureau of Statistics, 1995.

2 Heiler K, Pickersgill R, Briggs C. Shiftwork and rostering arrangements in the Australian Mining Industry. Geneva: ILO, 2000.

3 Lowden A, Kecklund G, Axelsson J, et al. Change from an 8-hour shift to a 12-hour shift, attitudes, sleep, sleepiness and performance. Scand J Work Environ Health 1998;24:69-75.

4 Gillberg M. Subjective alertness and sleep quality in connection with permanent 12-hour day and night shifts. Scand J Work Environ Health 1998;24:76-81.

5 Smith L, Folkard S, Tucker P. Work shift duration: a review comparing eight hour and 12 hour shift systems. Occup Environ Med 1998:55:217-29.

6 Axelsson J, Kecklund G, Akerstedt T, et al. Effects of alternating 8- and 12-hour shifts on sleep, sleepiness, physical effort and performance. Scand J Work Environ Health 1998;24:62-8

7 Colligan M, Rosa R. Shiftwork effects on social and family life. Occup Med 1990;5:315-22.

8 Rosa R, Colligan M. Extended workdays: effects of 8-hour and 12-hour rotating shift schedules on performance, subjective alertness, sleep patterns and psychosocial variables. Work and Stress 1989;3:21-32

9 Costa G. The problem: shiftwork. Chronobiol Int 1997; 14:89-98

10 Akerstedt T. Shift work and disturbed sleep/wakefulness. Sleep Med Rev 1998;2:117-28.

11 Spurgeon A, Harrington J, Cooper C. Health and safety problems associated with long working hours: a review of the current position. Occup Environ Med 1997;54:367-75.

12 Knutsson A, Boggild H. Shiftwork and cardiovascular disease: a review of disease mechanisms. Rev Environ Health 2000;15:359-72.
13 Taylor PJ, Pocock SJ, Sergean R. Absenteeism of shift and day workers. Br J Ind Med 1972;29:208-13.

14 Brown ID. Driver fatigue. Human Factors 1994;36:298-314

15 National Transportation Safety Board. Grounding of the U.S. tankship Exxon Valdez on Bligh Reef, Prince William Sound near Valdez, Alaska, March 24, 1989. Maritime Accident Report. NTSB/MAR-90/04. National Transportation Safety Board, 1990.

16 United States Nuclear Regulatory Commission. Report of the accident at the Chernobyl nuclear power station. NTIS NUREG 1250. January 1987.

17 Williamson AM. Changing the hours of shiftwork: a comparison of 8and 12-hour shift rosters in a small group of computer operators. Ergonomics 1994;37:287-98.

18 Jean-Louis G, Kripke DF, Ancoli-lsrael S. Sleep and quality of well-being. Sleep 2000;23:1115-21.

19 Bonnet MH. Sleep deprivation. In: Kryger MH, Roth T, Dement WC, eds. Principles and practice of sleep medicine. Philadelphia: WB Saunders Company, 1994:50-67.

20 Mitchell RJ, Williamson AM. Evaluation of an 8 hour versus a 12 hour shift roster on employees at a power station. Appl Ergon 2000;31:83-93

21 Belenky G, Balkin T, Redmond D, et al. Sustaining alertness during continuous operations: the US army's sleep management system. In: Hartley L, ed. Managing fatigue in transportation. Oxford: Elsevier Science Ltd, 1998.

22 Rosa RR. Extended workshifts and excessive fatigue. J Sleep Res 1995;4:51-6.

23 Duchon JC, Keran CM, Smith TJ. Extended workdays in an underground mine: a work performance analysis. Human Factors 1994;36:258-68.

24 Monk T. Subjective ratings of sleepiness - the underlying circadian mechanisms. Sleep 1987;10:343-53.

25 Monk T, Buysse D, Reynolds $\mathrm{Cl}$, et al. Circadian rhythms in human performance and mood under constant conditions. J Sleep Res 1997;6:9-18.

26 Folkard S, Monk T. Circadian performance rhythms. In: Folkard S, Monk $\mathrm{T}$, eds. Hours of work-temporal factors in work scheduling. New York: John Wiley \& Sons, 1985:37-52.

27 Hanecke K, Tiedemann S, Nachreiner F, et al. Accident risk as a function of hour at work and time of day as determined from accident data and exposure models for the German working population. Scand J Work Environ Health 1998;24:43-8.

28 Folkard S. Black times: temporal determinants of transport safety. Accid Anal Prev 1997;29:417-30. 